Jurnal Penelitian Karet, 2014, 32 (1) : 65 - 73

Indonesian J. Nat. Rubb. Res. 2014, 32 (1): 65 - 73

\title{
KARAKTERISASI MINYAK JARAK TERHIDROGENASI SEBAGAI BAHAN PELUNAK KARET ALAMI
}

\author{
Characterization of Hydrogenated Castor Oil as \\ Natural Plasticizer for Rubber Compound
}

\author{
Santi PUSPITASARI dan Adi CIFRIADI
}

Pusat Penelitian Karet

Jalan Salak Nomor 1 Bogor 16151

Email : shanty_bptkbgr@yahoo.co.id, cifriadi9748@gmail.com

Diterima : 19 Juli 2013 / Direvisi : 27 Agustus 2013 / Disetujui : 9 November 2013

\begin{abstract}
Hydrogenated castor oil (HCO) is expected as bio-based rubber plasticizer. Plasticizer must have good compatibility with rubber in order to achieve high mixing effectiveness. This research studied the performance and effect of $\mathrm{HCO}$ plasticizer in SIR 20 and EPDM 6250 rubber compound. HCO dosages were determined as 10 and $20 \mathrm{phr}$. The research was begun with rubber compounding, vulcanization and mechanical properties testing. The result showed that addition of $\mathrm{HCO}$ could reduce time and energy of compounding also weight loss procentage. Effect of hydrogenated castor oil on curing charactistic was highly marked in modulus decrease as a result of rubber molecule chain breakdown. Hydrogenated castor oil reduced hardness, tensile strength, and compression set but increase elongation of break and tear strength of SIR 20 and EPDM 6250 vulcanizate. Thus, hydrogenated castor oil can be used as bio-based rubber plasticizer especially on EPDM rubber compounding.
\end{abstract}

Keywords : Castor oil, rubber plasticizer, SIR 20, EPDM

\section{Abstrak}

Minyak jarak castor terhidrogenasi diharapkan dapat berfungsi sebagai bahan pelunak karet alami. Bahan pelunak harus memiliki kesesuaian yang baik dengan karet agar diperoleh efektifitas pencampuran yang tinggi. Percobaan ini akan mempelajari kinerja dan pengaruh minyak jarak castor terhidrogenasi sebagai bahan pelunak karet alami pada pembuatan kompon karet SIR 20 dan EPDM 6250 terhadap karakteristik vulkanisasi kompon dan sifat fisika vulkanisat karet. Dosis bahan pelunak ditetapkan 10 dan 20 bsk. Kinerja minyak jarak castor terhidrogenasi dibandingkan dengan bahan pelunak komersial golongan parafinik yaitu HVI 60 dan HVI 650. Tahapan dalam percobaan diawali dengan pembuatan kompon, kemudian vulkanisasi kompon dan pengujian sifat mekanik vulkanisat karet. Saat pembuatan kompon dilakukan pengamatan terhadap waktu dan konsumsi energi pengkomponan serta persentase kehilangan berat kompon. Hasil percobaan menunjukkan bahwa penambahan minyak jarak castor terhidrogenasi mampu menurunkan waktu dan energi pengkomponan serta persentase kehilangan berat kompon. Pengaruh minyak jarak castor terhidrogenasi pada karakteristik vulkanisasi sangat tampak pada penurunan modulus torsi sebagai akibat terputusnya rantai molekul karet. Penambahan minyak jarak castor terhidrogenasi juga menurunkan kekerasan, kekuatan tarik, dan pampatan tetap tetapi meningkatkan perpanjangan putus dan kekuatan sobek baik vulkanisat karet SIR 20 maupun EPDM 6250. Dengan demikian minyak jarak castor terhidrogenasi dapat digunakan sebagai bahan pelunak karet alami terutama dalam pembuatan kompon karet sintetik EPDM.

Kata kunci : Minyak jarak castor, bahan pelunak karet, SIR 20, EPDM

\section{PENDAHULUAN}

Minyak jarak castor terhidrogenasi merupakan salah satu bentuk modifikasi kimiawi dari minyak jarak castor yang diharapkan dapat berfungsi sebagai bahan pelunak karet alami (natural plasticizer). Pada kenyataannya penggunaan minyak jarak castor terhidrogenasi dapat lebih luas antara lain sebagai pelumas, pelapis, bahan pembantu dalam kosmetik, bahan pembantu untuk perekat, produksi lilin, pewarna, kapasitor listrik. Minyak jarak castor terhidrognasi juga memiliki potensi digunakan sebagai pengganti rolling oil komersial (Rivai, 2001). Dalam produksi barang jadi karet, warna minyak jarak castor 
yang terang memiliki keunggulan dibandingkan jenis bahan pelunak lain yang berwarna gelap karena penambahannya tidak terbatas pada produk karet berwarna gelap.

Hamed (2012) menuturkan bahwa bahan pelunak jenis physical plasticizer dapat bekerja dengan cara memutus rantai molekul karet, mengurangi ikatan, dan menurunkan gesekan (internal friction) antar molekul karet. Berdasarkan teori pelumasan (lubricity theory), fungsi bahan pelunak adalah mengurangi gesekan intermolekuler diantara molekul polimer karet. Bahan pelunak akan bekerja sebagai pelumas yang melumasi pergerakan molekul polimer karet dan mengurangi ketahanan molekul tersebut untuk meluncur (Wypych, 2004). France (2011) menyatakan bahwa bahan pelunak akan berada diantara rantai polimer dan menjaga agar rantai polimer tersebut saling terpisah sehingga mengurangi interaksi antar rantai polimer. Minyak jarak castor merupakan salah satu contoh physical plasticizer.

Penggunaan bahan pelunak yang menyebabkan terputusnya rantai molekul karet mengakibatkan viskositas karet menjadi rendah. Besarnya penurunan viskositas karet sangat bergantung pada dosis penambahan bahan pelunak. Penambahan bahan pelunak yang berlebihan akan menyebabkan pencampuran menjadi tidak efektif dan berpengaruh pada sifat fisika dan mekanik vulkanisat karet (Gupta, 1998). Bahan pelunak akan menurunkan modulus, kekuatan tarik, kekerasan, berat jenis, tetapi meningkatkan fleksibilitas, dan perpanjangan putus (Matthews, 1996 dalam Rahman dan Brazel, 2004).

Bahan pelunak digolongkan menjadi dua jenis yaitu bahan pelunak tipe primer dan sekunder (Krauskopf, 1993 dalam Rahman dan Brazel, 2004). Bahan pelunak primer digunakan sebagai bahan pelunak utama sedangkan bahan pelunak sekunder dikombinasikan dengan bahan pelunak primer untuk meningkatkan sifat mekanik dan menurunkan biaya saat pembuatan barang jadi karet. Oleh karena itu pemilihan bahan pelunak perlu memperhatikan kriteria antara lain tingkat kesesuaian bahan pelunak dengan polimer karet, karakteristik pemrosesan, pengaruh bahan pelunak terhadap sifat rheologi polimer, dan biaya (Gachter dan Muller, 1990 dalam Rahman dan Brazel, 2004).

Bahan pelunak harus memiliki tingkat kecocokan (kompatibilitas) yang tinggi dengan karet dan stabil saat digunakan pada suhu tinggi maupun rendah sehingga mampu memberikan efektifitas pencampuran yang baik (Rahman dan Brazel, 2004). Efektifitas pencampuran dan kompatibilitas karet dengan bahan pelunak dipengaruhi oleh struktur kimia, berat molekul, gugus fungsi dalam struktur molekul, serta kelarutan bahan pelunak tersebut (Rahman dan Brazel, 2004). Tingkat ketidak-cocokan karet dengan bahan pelunak ditandai dengan merembesnya bahan pelunak melalui pori-pori dipermukaan vulkanisat karet (Gent, 2001). Struktur molekul minyak jarak castor terhidrogenasi tersusun atas asam-asam lemak rantai lurus yang dikenal dengan asam lemak risinoleat. Struktur molekul rantai lurus juga ditemui pada bahan pelunak golongan minyak parafinik. Bahan pelunak golongan minyak parafinik banyak diaplikasikan untuk karet yang bersifat non polar seperti karet EPDM dan IIR.

Pada percobaan ini akan dipelajari kinerja dan pengaruh minyak jarak castor terhidrogenasi sebagai bahan pelunak karet alami pada pembuatan kompon karet alam SIR 20 dan karet sintetik EPDM 6250 terhadap karakteristik vulkanisasi kompon dan sifat mekanik vulkanisat karet.

\section{BAHAN DAN METODE}

Uji coba minyak jarak castor terhidrogenasi sebagai bahan pelunak dalam pembuatan kompon telah dilakukan di Pabrik Percobaan Pusat Penelitian Karet sejak bulan Agustus hingga Oktober 2012. Karet yang digunakan dalam percobaan terdiri atas karet alam SIR 20 dan karet sintetik EPDM 6250. Bahan kimia karet yang digunakan dalam percobaan berada pada spesifikasi teknis. Formulasi kompon karet mengikuti formula kompon karet yang digunakan oleh Crowther (1983) seperti disajikan pada Tabel 1 .

Minyak jarak castor terhidrogenasi yang digunakan memiliki derajat hidrogenasi sebesar $40,80 \%$ dengan 
Tabel 1. Fomula kompon karet

Table 1. Rubber compound formulae

\begin{tabular}{|c|c|c|c|c|c|c|c|}
\hline \multirow[t]{2}{*}{ No } & \multirow[t]{2}{*}{$\begin{array}{c}\text { Bahan kimia } \\
\text { Chemicals }\end{array}$} & \multicolumn{3}{|c|}{$\begin{array}{c}\text { Dosis } \\
\text { (bsk) } \\
\text { Dosage } \\
\text { (phr) }\end{array}$} & \multicolumn{3}{|c|}{$\begin{array}{l}\text { Berat } \\
\text { Weight } \\
\text { (g) }\end{array}$} \\
\hline & & $\begin{array}{l}\text { Kontrol } \\
\text { Control }\end{array}$ & 10 & 20 & $\begin{array}{l}\text { Kontrol } \\
\text { Control }\end{array}$ & 10 & 20 \\
\hline 1 & Karet & 100 & 100 & 100 & 317,86 & 298,86 & 282,01 \\
\hline 2 & $\mathrm{ZnO}$ & 5 & 5 & 5 & 15,89 & 14,94 & 14,10 \\
\hline 3 & Asam stearat & 2,5 & 2,5 & 2,5 & 7,95 & 7,47 & 7,05 \\
\hline 4 & Carbon black 220 & 45 & 45 & 45 & 143,04 & 134,49 & 126,90 \\
\hline 5 & TMQ & 1,5 & 1,5 & 1,5 & 4,77 & 4,48 & 4,23 \\
\hline 6 & Bahan pelunak & 0 & 10 & 20 & - & 29,89 & 56,40 \\
\hline 7 & CBS & 0,8 & 0,8 & 0,8 & 2,54 & 2,39 & 2,26 \\
\hline \multirow[t]{2}{*}{8} & Sulfur & 2,5 & 2,5 & 2,5 & 7,95 & 7,47 & 7,05 \\
\hline & Total & 157,3 & 167,3 & 177,3 & 500,00 & 500,00 & 500,00 \\
\hline
\end{tabular}

Bsk $=$ berat seratus karet $(p h r=$ per hundred rubber $)$

bilangan iod sebesar 49,21. Berdasarkan bilangan iodnya, minyak jarak castor terhidrogenasi tersebut dapat digolongkan sebagai bahan pelunak yang berasal dari minyak nabati terhidrogenasi tipe II. Ash dan Ash (2007) mempersyaratkan bahwa minyak nabati terhidrogenasi yang digunakan sebagai bahan pelunak tipe II memiliki bilangan iod sebesar 55-80.

Dosis minyak jarak castor terhidrogenasi ditetapkan sebesar 10 dan 20 bsk. Penetapan dosis bahan pelunak didasarkan pada jumlah bahan pelunak yang ditambahkan dalam pembuatan ban kendaraan yang umumnya sebesar $8-20 \%$. Untuk mengetahui optimalisasi kinerja minyak jarak castor terhidrogenasi sebagai bahan pelunak karet maka minyak jarak castor dibandingkan dengan bahan pelunak komersial golongan minyak parafinik yaitu HVI 60 dan HVI 650. Spesifikasi dari masingmasing bahan pelunak komersial tersebut diuraikan pada Tabel 2.

Tabel 2. Sifat minyak parafinik golongan HVI 60 dan HVI 650

Table 2. Properties of paraffinic oil types HVI 60 and HVI 650

\begin{tabular}{|c|c|c|c|c|}
\hline \multirow[t]{2}{*}{ No } & \multirow{2}{*}{$\begin{array}{c}\text { Sifat } \\
\text { Properties }\end{array}$} & \multirow{2}{*}{$\begin{array}{l}\text { Metode } \\
\text { Method }\end{array}$} & \multicolumn{2}{|c|}{$\begin{array}{c}\text { Minyak parafinik } \\
\text { Paraffinic oil }\end{array}$} \\
\hline & & & HVI 60 & HVI 650 \\
\hline 1 & $\begin{array}{l}\text { Kekentalan pada } 100^{\circ} \mathrm{C}, \mathrm{cSt} \\
\text { Viscosity }\end{array}$ & ASTM 0-445 & $4,4-4,9$ & $30,5-33,5$ \\
\hline 2 & $\begin{array}{l}\text { Indeks kekentalan (min) } \\
\text { Viscosity index }\end{array}$ & ASTM 0-2270 & 95 & 95 \\
\hline 3 & $\begin{array}{l}\text { Titik nyala, }{ }^{\circ} \mathrm{C}(\mathrm{min}) \\
\text { Flash point } P M C C\end{array}$ & ASTM D-93 & 204 & 267 \\
\hline 4 & $\begin{array}{l}\text { Titik tuang, }{ }^{\circ} \mathrm{C} \text { (max) } \\
\text { Pour point }\end{array}$ & ASTM D-97 & -15 & -9 \\
\hline 5 & $\begin{array}{l}\text { Keasaman, mg KOH/g (max) } \\
\text { Total acidity }\end{array}$ & ASTM D-974 & 0,05 & 0,05 \\
\hline 6 & $\begin{array}{l}\text { Kadar abu, \% wt ( } \max ) \\
\text { Ash content }\end{array}$ & ASTM 0-482 & 0,01 & 0,01 \\
\hline 7 & $\begin{array}{l}\text { Warna, ASTM (max) } \\
\text { Color }\end{array}$ & ASTM 0-1500 & 1,5 & 4,0 \\
\hline 8 & $\begin{array}{l}\text { Visualisasi } \\
\text { Appearance }\end{array}$ & Visual & $\begin{array}{c}\text { Terang } \\
\text { Clear \& bright }\end{array}$ & $\begin{array}{c}\text { Terang } \\
\text { Clear \& bright }\end{array}$ \\
\hline
\end{tabular}

Sumber (Source) : www.pertamina.com 
Pembuatan kompon diawali dengan mastikasi karet hingga lunak sehingga mudah bercampur dengan bahan kimia. Selanjutnya ke dalam karet yang telah lunak ditambahkan bahan kimia secara berurutan mulai dari $\mathrm{ZnO}$, asam stearat, Carbon Black N 220 bersamaan dengan bahan pelunak, TMQ, CBS, dan terakhir sulfur. Saat pembuatan kompon karet, waktu dan konsumsi energi diamati begitu pula dengan kehilangan berat kompon turut diperhitungkan. Kompon karet yang telah terbentuk dicuplik sebanyak 50 gram untuk uji karakteristik vulkanisasi menggunakan Rheometer, sedangkan sisa kompon divulkanisasi agar terbentuk vulkanisat karet. Vulkanisat karet diuji sifat mekanik meliputi uji kekerasan (shore A), kuat tarik dan perpanjangan putus pada kondisi sebelum dan sesudah pengusangan $\left(70^{\circ} \mathrm{C}\right.$ selama 7 hari), uji kuat sobek, dan uji pampatan tetap (compression set) pada kondisi $100^{\circ} \mathrm{C}$ selama 24 jam serta $70^{\circ} \mathrm{C}$ selama 7 hari.

\section{HASIL DAN PEMBAHASAN}

Pada saat pembuatan kompon dalam mesin giling terbuka dilakukan pengamatan tentang waktu dan energi yang diperlukan dalam pengkomponan serta kehilangan berat kompon. Parameter-parameter tersebut berkaitan erat dengan fungsi bahan pelunak dalam pembuatan kompon karet. Hasil pengamatan terinci dalam Tabel 3.

Berdasarkan Tabel 3 dapat diketahui bahwa penambahan bahan pelunak baik minyak jarak terhidrogenasi (HCO) maupun minyak parafinik (HVI 60 dan HVI 650) dapat meningkatkan effisiensi pengkomponan karet dengan cara menurunkan waktu dan menggurangi konsumsi energi pengkomponan. Kompon karet kontrol (tanpa penambahan bahan pelunak) memiliki waktu dan konsumsi energi pengkomponan tertinggi. Hal ini disebabkan karena tanpa penambahan bahan pelunak, waktu yang diperlukan untuk membuat karet menjadi plastis dan mudah bercampur dengan bahan kimianya menjadi lebih lama akibatnya mengkonsumsi energi yang lebih besar. Penambahan dosis bahan pelunak dari 10 bsk menjadi 20 bsk turut mempersingkat waktu pengkomponan pada kompon karet SIR 20 sedangkan pada kompon karet EPDM 6250 tidak menunjukkan beda nyata. Pada kedua kompon karet, kinerja bahan pelunak dari minyak jarak terhidrogenasi relatif sama dengan bahan pelunak HVI 60 dan HVI 650 baik dari segi waktu maupun energi yang diperlukan untuk pengkomponan.

Tabel 3. Kinerja minyak jarak castor terhidrogenasi saat pembuatan kompon Table 3. Perfomance of hydrogenated castor oil at rubber compounding

\begin{tabular}{|c|c|c|c|c|c|c|}
\hline \multirow[b]{2}{*}{$\begin{array}{l}\text { Sampel } \\
\text { Sample }\end{array}$} & \multicolumn{3}{|c|}{$\begin{array}{l}\text { Kompon karet SIR } 20 \\
\text { SIR } 20 \text { rubber compound }\end{array}$} & \multicolumn{3}{|c|}{$\begin{array}{l}\text { Kompon karet EPDM } 6250 \\
\text { EPDM } 6250 \text { rubber compound }\end{array}$} \\
\hline & $\begin{array}{c}\text { Waktu } \\
\text { Time } \\
\text { (menit) }\end{array}$ & $\begin{array}{c}\text { Konsumsi } \\
\text { energi } \\
\text { Energy } \\
\text { consumption } \\
\text { (Kwatt) }\end{array}$ & $\begin{array}{c}\text { Kehilangan } \\
\text { berat } \\
\text { Weight } \\
\text { Loss } \\
(\%)\end{array}$ & $\begin{array}{c}\text { Waktu } \\
\text { Time } \\
\text { (menit) }\end{array}$ & $\begin{array}{c}\text { Konsumsi } \\
\text { energi } \\
\text { Energy } \\
\text { consumption } \\
\text { (Kwatt) }\end{array}$ & $\begin{array}{c}\text { Kehilangan } \\
\text { berat } \\
\text { Weight } \\
\text { Loss } \\
(\%)\end{array}$ \\
\hline Kontrol & 17 & 2,13 & 5,66 & 12 & 1,50 & 2,01 \\
\hline \multicolumn{7}{|c|}{ Dosis bahan pelunak $=10 \mathrm{bsk}$} \\
\hline $\mathrm{HCO}$ & 15 & 1,88 & 5,97 & 10 & 1,25 & 5,28 \\
\hline HVI 60 & 16 & 2,00 & 5,78 & 10,5 & 1,31 & 1,21 \\
\hline HVI 650 & 16 & 2,00 & 6,07 & 10 & 1,25 & 1,45 \\
\hline \multicolumn{7}{|c|}{ Dosis bahan pelunak $=20 \mathrm{bsk}$} \\
\hline $\mathrm{HCO}$ & 14 & 1,75 & 2,13 & 10 & 1,25 & 2,16 \\
\hline HVI 60 & 13 & 1,63 & 2,08 & 10 & 1,25 & 1,26 \\
\hline HVI 650 & 12,5 & 1,56 & 1,90 & 10 & 1,25 & 1,55 \\
\hline
\end{tabular}


Pada perhitungan kehilangan berat kompon karet SIR 20, dosis penambahan bahan pelunak sebesar 10 bsk menunjukkan hasil yang lebih tinggi dibandingkan kehilangan berat kompon pada kompon kontrol namun pada dosis bahan pelunak sebesar 20 bsk terjadi penurunan persentase kehilangan berat kompon secara signifikan. Peningkatan dosis bahan pelunak dari minyak jarak castor terhidrogenasi turut menurunkan kehilangan berat kompon karet EPDM 6250 dari 5,28\% menjadi 2,16\%. Rendahnya persentase kehilangan berat kompon mengindikasikan tingginya efektivitas pencampuran. Saat pembuatan kompon karet, bahan pelunak ditambahkan bersaman dengan bahan pengisi (carbon black). Carbon black yang digunakan dalam kompon karet umumnya memiliki ukuran partikel yang relatif besar dan ditambahkan dalam porsi yang cukup banyak sehingga sukar bercampur dengan karet. Dengan adanya bahan pelunak turut membantu pencampuran agar tidak terlalu banyak carbon black yang terjatuh melalui celah antar dua roll saat pengkomponan. Dosis bahan pelunak yang semakin banyak menyebabkan fungsinya menjadi lebih optimal. Penambahan bahan pelunak disajikan pada Gambar 1 dan 2.
Hasil pengujian karakteristik vulkanisasi kompon karet diperlukan sebagai dasar untuk menetapkan kondisi operasi vulkanisasi kompon karet. Uji karakteristik vulkanisasi dilakukan pada suhu $150^{\circ} \mathrm{C}$. Hasil pengujian karakteristik vulkanisasi kompon karet disajikan pada Tabel 4.

Pengujian karakteristik vulkanisasi memberikan informasi tentang derajat pengikatan silang antar molekul karet yang dijembatani oleh sulfur berdasarkan nilai modulus torsi (S), waktu vulkanisasi optimal (t90), dan waktu pra vulkanisasi (ts2). Penggunaan bahan pelunak yang mengakibatkan terputusnya rantai molekul karet menjadi rantai molekul yang lebih pendek menyebabkan pembentukan ikatan silang antar molekul karet terjadi antar molekul karet yang pendek sehingga derajat ikatan silang menjadi rendah. Hal ini ditunjukkan oleh menurunnya nilai modulus torsi kompon karet dalam pengujian karakteristik vulkanisasi dibandingkan dengan nilai modulus torsi karet tanpa penambahan bahan pelunak (kontrol). Efek ini semakin terlihat seiring peningkatan dosis bahan pelunak dalam pembuatan kompon karet SIR 20 maupun EPDM 6250.
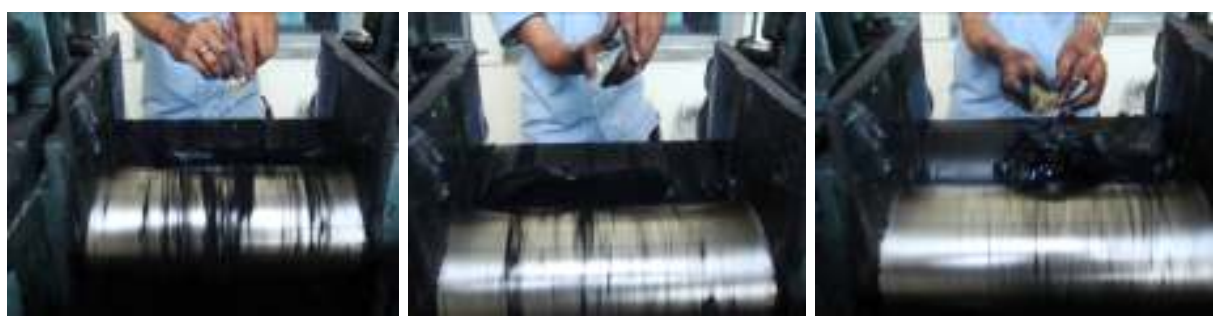

Gambar 1. Penambahan bahan pelunak dalam matriks karet SIR 20 Figure 1. Addition of plasticizer at SIR 20 rubber matrix (a) HCO, (b) HVI 60, (c) HVI 650
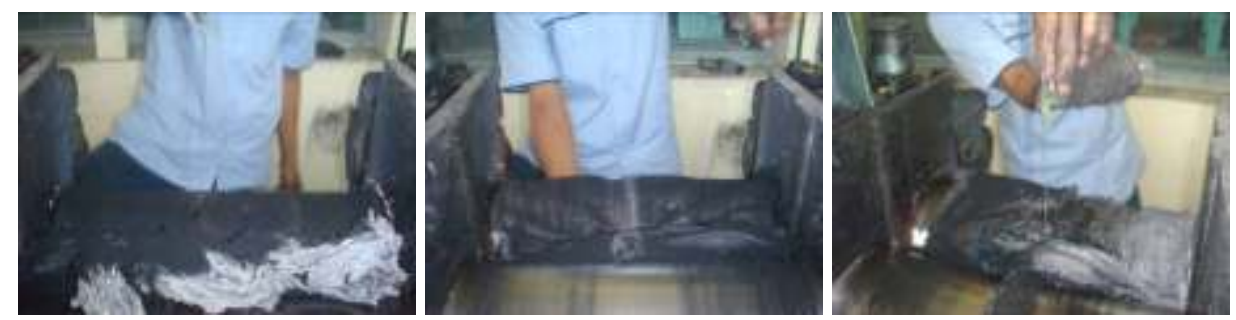

Gambar 2. Penambahan bahan pelunak dalam matriks karet EPDM 6250 Figure 2. Addition of plasticizer at EPDM 6250 rubber matrix

(a) HCO, (b) HVI 60, (c) HVI 650 
Tabel 4. Karakteristik vulkanisasi kompon karet

Table 4. Characteristic vulcanization of rubber compound

\begin{tabular}{|c|c|c|c|c|c|c|c|c|c|c|}
\hline \multirow[b]{2}{*}{$\begin{array}{l}\text { Sampel } \\
\text { Samples }\end{array}$} & \multicolumn{5}{|c|}{$\begin{array}{l}\text { Kompon karet SIR } 20 \\
\text { SIR } 20 \text { rubber compound }\end{array}$} & \multicolumn{5}{|c|}{$\begin{array}{l}\text { Kompon karet EPDM } 6250 \\
\text { EPDM } 6250 \text { rubber compound }\end{array}$} \\
\hline & $\begin{array}{l}\mathrm{S} \operatorname{Max} \\
(\mathrm{kgcm})\end{array}$ & $\begin{array}{c}\mathrm{S} \\
\mathrm{Min} \\
(\mathrm{kgcm})\end{array}$ & $\begin{array}{c}\Delta \mathrm{S} \\
(\mathrm{kgcm})\end{array}$ & $\begin{array}{c}\text { t90 } \\
\text { (menit) }\end{array}$ & $\begin{array}{c}\text { ts } 2 \\
\text { (menit) }\end{array}$ & $\begin{array}{l}\mathrm{S} \operatorname{Max} \\
(\mathrm{kgcm})\end{array}$ & $\begin{array}{c}\mathrm{S} \\
\mathrm{Min} \\
(\mathrm{kgcm})\end{array}$ & $\begin{array}{c}\Delta \mathrm{S} \\
(\mathrm{kgcm})\end{array}$ & $\begin{array}{c}\text { t90 } \\
\text { (menit) }\end{array}$ & $\begin{array}{c}\text { ts2 } \\
\text { (menit) }\end{array}$ \\
\hline Kontrol & 14,93 & 1,43 & 13,50 & 10,46 & 2,27 & 19,59 & 2,82 & 16,77 & 45,48 & 4,51 \\
\hline \multicolumn{11}{|c|}{ Dosis bahan pelunak $=10 \mathrm{bsk}$} \\
\hline $\mathrm{HCO}$ & 10,81 & 1,15 & 9,66 & 10,23 & 2,57 & 11,63 & 2,53 & 9,10 & 46,02 & 6,41 \\
\hline HVI 60 & 10,61 & 1,17 & 9,44 & 11,27 & 3,10 & 17,81 & 2,38 & 15,43 & 46,09 & 5,33 \\
\hline HVI 650 & 10,91 & 1,07 & 9,84 & 11,49 & 3,09 & 17,78 & 2,88 & 14,90 & 46,12 & 6,00 \\
\hline \multicolumn{11}{|c|}{ Dosis bahan pelunak $=20 \mathrm{bsk}$} \\
\hline $\mathrm{HCO}$ & 7,70 & 0,79 & 6,91 & 11,02 & 3,45 & 7,64 & 1,69 & 5,95 & 44,15 & 10,52 \\
\hline HVI 60 & 8,07 & 0,79 & 7,28 & 12,28 & 3,55 & 14,09 & 1,99 & 12,10 & 47,02 & 7,04 \\
\hline HVI 650 & 7,52 & 0,64 & 6,88 & 13,09 & 4,18 & 14,69 & 2,33 & 12,36 & 46,33 & 7,05 \\
\hline
\end{tabular}

Pada dosis 10 bsk, bahan pelunak dari golongan minyak jarak castor terhidrogenasi memberikan waktu vulkanisasi optimal lebih cepat dibandingkan kompon kontrol karet SIR 20. Adanya kandungan asam stearat dalam minyak jarak castor terhidrogenasi turut berpengaruh terhadap laju vulkanisasi kompon karet SIR 20. Asam stearat yang dikombinasikan dengan $\mathrm{ZnO}$ berfungsi sebagai aktivator dalam sistem vulkanisasi belerang. Tetapi pada dosis 20 bsk, penambahan minyak jarak castor terhidrogenasi justru memperlambat laju vulkanisasi sehingga waktu vulkanisasi optimal menjadi panjang. Sifat basa pada minyak jarak castor terhidrogenasi menghambat laju vulkanisasi karet SIR 20. Pada dosis penambahan minyak jarak castor yang tinggi, sifat basa ini semakin besar pengaruhnya terhadap laju vulkanisasi. Hal sebaliknya terjadi pada kompon karet EPDM 6250. Penambahan minyak jarak castor terhidrogenasi pada dosis $10 \mathrm{bsk}$ menyebabkan waktu vulkanisasi optimal lebih lambat dibandingkan kompon kontrol namum pada dosis 20 bsk, justru mempercepat waktu vulkanisasi optimal.

Pada parameter waktu pra vulkanisasi, penambahan bahan pelunak dalam kompon karet SIR 20 maupun EPDM 6250 cenderung memperlama waktu pra vulkanisasi. Terputusnya rantai molekul karet akibat kerja bahan pelunak dan adanya pengaruh panas mengakibatkan pada awal proses vulkanisasi terbentuknya ikatan silang antar molekul karet tersebut menjadi lama.

Visualisasi vulkanisat karet SIR 20 dengan penambahan bahan pelunak dari minyak jarak castor terhidrogenasi tampak bahwa minyak jarak castor terhidrogenasi merembes keluar permukaan vulkanisat karet SIR 20 tersebut. Hal ini mengindikasikan bahwa minyak jarak castor terhidrogenasi tidak sesuai (incompatible) dengan karet alam SIR 20 karena adanya perbedaan polaritas meskipun memiliki efek pelunakan yang tergolong baik (terlihat dari rendahnya nilai modulus torsi pada pengujian karakteristik vulkanisasi). Sedangkan pada vulkanisat karet sintetik EPDM 6250, minyak jarak castor terhidrogenasi tidak merembes melalui permukaan vulkanisat. Aplikasi minyak jarak castor terhidrogenasi dalam karet sintetik EPDM 6250 cukup efektif karena memberikan nilai modulus torsi paling rendah dibandingkan bahan pelunak lain (HVI 60 dan 650).

Parameter dalam pengujian sifat mekanik vulkanisat yang digunakan sebagai tolak ukur kinerja bahan pelunak terdiri atas kekerasan, kekuatan tarik, perpanjangan putus, pampatan tetap, dan kuat sobek. Pengujian dilakukan sebelum dan setelah pengusangan. Hasil pengujian sifat mekanik 
vulkanisat disajikan dalam Tabel 5 untuk vulkanisat dengan karet SIR 20 dan Tabel 6 untuk vulkanisat dengan karet EPDM 6250.

Kekerasan vulkanisat karet SIR 20 berkurang seiring dengan penambahan bahan pelunak. Pada penambahan dosis bahan pelunak sebesar 10 bsk mampu menurunkan kekerasan vulkanisat hingga 10 satuan sedangkan pada dosis bahan pelunak sebesar 20 bsk, penurunan kekerasan mencapai 20 satuan. Bahan pelunak jenis minyak pelunak (rubber processing oil) memberikan pengaruh penurunan kekerasan terhadap vulkanisat karet. Pada pengujian setelah pengusangan, kekerasan vulkanisat mengalami peningkatan dibandingkan sebelum pengusangan.

Kekuatan tarik menjadi salah satu indikator terjadi perubahan dalam struktur molekul vulkanisat karet akibat penambahan bahan pelunak. Kekuatan tarik dan perpanjangan putus menggambarkan elastistas vulkanisat karet. Penambahan bahan pelunak menurunkan kekuatan tarik tetapi meningkatkan perpanjangan putus. Kedua sifat tersebut berkaitan dengan derajat ikatan silang pada vulkanisat yang terbentuk dari rantai molekul karet yang telah pendek akibat kerja bahan pelunak.

Tabel 5. Sifat mekanik vulkanisat SIR 20

Table 5. Mechanical properties of SIR 20 vulcanizate

\begin{tabular}{|c|c|c|c|c|c|c|c|c|c|}
\hline \multirow[b]{2}{*}{$\begin{array}{l}\text { Sampel } \\
\text { Samples }\end{array}$} & \multicolumn{3}{|c|}{$\begin{array}{c}\text { Sebelum pengusangan } \\
\text { Before ageing }\end{array}$} & \multicolumn{3}{|c|}{$\begin{array}{c}\text { Setelah pengusangan } \\
\text { After ageing }\end{array}$} & \multicolumn{2}{|c|}{$\begin{array}{l}\text { Pampatan tetap } \\
\text { Compression set } \\
(\%)\end{array}$} & \multirow{2}{*}{$\begin{array}{c}\text { Kekuatan } \\
\text { sobek } \\
\text { Tear } \\
\text { strenght } \\
(\mathrm{N} / \mathrm{mm})\end{array}$} \\
\hline & $\begin{array}{c}\text { Kekerasan } \\
\text { Hardness } \\
\text { (Shore A) }\end{array}$ & $\begin{array}{c}\text { Kuat tarik } \\
\text { Tensile } \\
\text { strenght } \\
\left(\mathrm{N} / \mathrm{mm}^{2}\right)\end{array}$ & $\begin{array}{c}\text { Perpanjangan } \\
\text { putus } \\
\text { Elongation at } \\
\text { breaks } \\
(\%)\end{array}$ & $\begin{array}{l}\text { Kekerasan } \\
\text { Hardness } \\
\text { (Shore A) }\end{array}$ & $\begin{array}{c}\text { Kuat } \\
\text { tarik } \\
\text { Tensile } \\
\text { strenght } \\
\left(\mathrm{N} / \mathrm{mm}^{2}\right)\end{array}$ & $\begin{array}{c}\text { Perpanjangan } \\
\text { putus } \\
\text { Elongation } \\
\text { at breaks } \\
(\%)\end{array}$ & $\begin{array}{c}100^{\circ} \mathrm{C} / \\
24 \mathrm{jam} \\
100^{\circ} \mathrm{C} / \\
24 \\
\text { hours }\end{array}$ & $\begin{array}{l}70^{\circ} \mathrm{C} / \\
7 \text { hari } \\
70^{\circ} \mathrm{C} / \\
7 \text { days }\end{array}$ & \\
\hline Kontrol & 68 & 22,0 & 460 & 71 & 22,1 & 410 & 53,61 & 66,67 & 79,5 \\
\hline \multicolumn{10}{|c|}{ Dosis bahan pelunak $=10 \mathrm{bsk}$} \\
\hline $\mathrm{HCO}$ & 58 & 17,5 & 480 & 60 & 21,8 & 510 & 55,96 & 69,62 & 80,1 \\
\hline HVI 60 & 58 & 19,4 & 510 & 65 & 21,2 & 460 & 64,35 & 76,10 & 74,5 \\
\hline HVI 650 & 60 & 18,2 & 480 & 65 & 20,1 & 440 & 61,0 & 77,02 & 66,6 \\
\hline \multicolumn{10}{|c|}{ Dosis bahan pelunak $=20 \mathrm{bsk}$} \\
\hline $\mathrm{HCO}$ & 46 & 17,9 & 610 & 53 & 18,2 & 530 & 63,02 & 78,71 & 64,6 \\
\hline HVI 60 & 46 & 15,6 & 510 & 52 & 18,1 & 500 & 65,29 & 81,73 & 60,9 \\
\hline HVI 650 & 48 & 15,9 & 510 & 56 & 18,0 & 490 & 67,30 & 82,69 & 49,8 \\
\hline
\end{tabular}


Tabel 6. Sifat mekanik vulkanisat EPDM 6250

Table 6. Mechanical properties of EPDM 6250 vulcanizate

\begin{tabular}{|c|c|c|c|c|c|c|c|c|c|}
\hline \multirow{2}{*}{$\begin{array}{l}\text { Sampel } \\
\text { Sample }\end{array}$} & \multicolumn{3}{|c|}{$\begin{array}{l}\text { Sebelum pengusangan } \\
\text { Before ageing }\end{array}$} & \multicolumn{3}{|c|}{$\begin{array}{l}\text { Setelah pengusangan } \\
\text { After ageing }\end{array}$} & \multicolumn{2}{|c|}{$\begin{array}{c}\text { Pampatan } \\
\text { tetap } \\
\text { Compression } \\
\text { set } \\
(\%)\end{array}$} & \multirow[t]{2}{*}{$\begin{array}{c}\text { Kekuatan } \\
\text { sobek } \\
\text { Tear } \\
\text { strenght } \\
(\mathrm{N} / \mathrm{mm})\end{array}$} \\
\hline & $\begin{array}{l}\text { Kekerasan } \\
\text { Hardness } \\
\text { (Shore A) }\end{array}$ & $\begin{array}{c}\text { Kuat } \\
\text { tarik } \\
\text { Tensile } \\
\text { strenght } \\
\left(\mathrm{N} / \mathrm{mm}^{2}\right)\end{array}$ & $\begin{array}{l}\text { Perpanjangan } \\
\text { putus } \\
\text { Elongation at } \\
\text { breaks } \\
(\%)\end{array}$ & $\begin{array}{c}\text { Kekerasan } \\
\text { Hardness } \\
\text { (Shore A) }\end{array}$ & $\begin{array}{c}\text { Kuat } \\
\text { tarik } \\
\text { Tensile } \\
\text { strenght } \\
\left(\mathrm{N} / \mathrm{mm}^{2}\right)\end{array}$ & $\begin{array}{c}\text { Perpanjangan } \\
\text { putus } \\
\text { Elongation at } \\
\text { breaks } \\
(\%)\end{array}$ & $\begin{array}{c}100^{\circ} \mathrm{C} / \\
24 \mathrm{jam} \\
100^{\circ} \mathrm{C} / \\
24 \\
\text { hours }\end{array}$ & $\begin{array}{l}70^{\circ} \mathrm{C} / \\
7 \text { hari } \\
70^{\circ} \mathrm{C} / \\
7 \text { days }\end{array}$ & \\
\hline Kontrol & 72 & 23,7 & 600 & 73 & 15,68 & 580 & 65,62 & 55,41 & 43,9 \\
\hline $\begin{array}{l}\text { HCO } \\
\text { HVI } 60 \\
\text { HVI } 650 \\
\end{array}$ & $\begin{array}{l}55 \\
63 \\
65 \\
\end{array}$ & $\begin{array}{c}7,8 \\
23,8 \\
18,4 \\
\end{array}$ & $\begin{array}{ll} & \text { Dos } \\
650 & \\
710 & \\
610 & \\
\end{array}$ & $\begin{array}{c}\text { bahan pelu } \\
60 \\
65 \\
67 \\
\end{array}$ & $\begin{array}{c}\mathrm{ak}=20 \mathrm{bs} \\
44,98 \\
13,72 \\
0,47 \\
\end{array}$ & $\begin{array}{l}640 \\
690 \\
590 \\
\end{array}$ & $\begin{array}{l}61,74 \\
73,34 \\
73,07 \\
\end{array}$ & $\begin{array}{l}63,52 \\
69,16 \\
59,42 \\
\end{array}$ & $\begin{array}{l}32,4 \\
36,2 \\
37,1 \\
\end{array}$ \\
\hline
\end{tabular}

\section{KESIMPULAN DAN SARAN}

Minyak jarak castor terhidrogenasi dapat digunakan sebagai bahan pelunak karet alami terutama dalam pembuatan kompon karet sintetik EPDM 6250. Hal ini disebabkan karena minyak jarak castor terhidrogenasi memiliki kinerja yang baik sebagai bahan pelunak karet EPDM 6250 yang ditandai dengan waktu dan energi pengkomponan yang rendah serta menurunkan modulus torsi pada kompon karet EPDM 6250 saat pengujian karakteristik vulkanisasi. Kompatibilitas karet EPDM 6250 dengan minyak jarak castor terhidrogenasi juga terlihat dengan tidak merembesnya minyak jarak castor terhidrogenasi melalui pori-pori di permukaan vulkanisat karet EPDM 6250.

Evaluasi lanjut terhadap kinerja minyak jarak castor terhidrogenasi perlu dilakukan pada jenis karet yang lain misalnya pada karet butyl (IIR). Dengan demikian dapat diketahui berbagai jenis karet sintetik yang sesuai dengan bahan pelunak golongan minyak jarak castor terhidrogenasi, tidak terbatas hanya pada karet EPDM.

\section{DAFTAR PUSTAKA}

Ash, M, and I. Ash. 2007. Handbook of Fillers, Extender, and Diluents, $2^{\text {nd }}$ Edition. Synapse Information Resources Inc, New York.

Crowther, B.G. 1973. Effect of Process Oils on the Vulcanizate Properties of Natural Rubber Treadstock, NR Technology 14(4): $79-84$

France, Colin. 2011. Polimer-Bahan Pelunak. www.gcsescience.com diakses tanggal 14 Mei 2012

Gachter. R, and H. Muller. 1990. Plastics Additives Handbook. $3^{\text {rd }}$ ed. Carl Henser, New York

Gent, A. N. 2001. Engineering with Rubber. How to Design Rubber Component. $2^{\text {nd }}$ Edition. Hanser Gadner Publication Inc, Ohio.

Gupta, B.R. 1998. Rubber Processing on a Two Roll Mill. Allied Publisher Limited, New Delhi. 
Hamed, G. R. 2012. Materials and Compounds. www.gupta-verlag.de diakses tanggal 25 April 2012

Krauskopf, L. G. 1993. Monomeric Plasticizers. In : Wickson EJ Editor. Handbook of PVC Formulating. Willey, New York

Matthews, G. 1996. PVC : Production, Properties and Uses. Institute of Metal, London

Pertamina. 2013. Lube Base Oil. Pertamina, Jakarta. www.pertamina.com, diakses tanggal 2 Januari 2013
Rahman, M, and C. S. Brazel. 2004. The Plasticizer Market : an Assessment of Traditional Plasticizer and Research Trends to Meet New Challenges. Prog. Polym. Sci. 29 : 1223-1248

Rivai, Mira. 2001. Kajian Proses Hidrogenasi Minyak Sawit Pada Berbagai Tingkat Kemurnian Dalam Rangka Menghasilkan Pelumas Dasar Untuk Rolling Oil. Skripsi. Fakultas Teknologi Pertanian, Institut Pertanian Bogor, Bogor

Wypych, G. 2004, Handbook of Plasticizers. ChemTec Publishing, Canada 